\title{
En dialog om kolonialitet och socialt arbete som akademiskt ämne
}

Lena Sawyer är docent i socialt arbete och universitetslektor vid Institutionen för socialt arbete, Göteborgs Universitet.

Hanna Wikström är docent i socialt arbete och universitetslektor vid Institutionen för socialt arbete, Göteborgs Universitet.

Adrián Groglopo är lektor i socialt arbete och universitetslektor vid Institutionen för socialt arbete, Göteborgs Universitet.

Maimuna Abdullahi är doktorand vid Institutionen för socialt arbete, Göteborgs Universitet.

Kontakt: lena.sawyer@socwork.gu.se

\section{Inledning}

Vad kan förståelsen av begreppen kolonialitet, epistemicide och locus of enunciation innebära i och för socialt arbete? Under några veckor i januari 2020 diskuterade vi - fyra akademiker med olika ingångar, bakgrunder och positioner inom universitetet - detta genom en kollaborativ skrivprocess. Vi hörsammar Satu Ranta-Tyrrkös (2011) uppmaning om att det är hög tid för postkoloniala analyser (även) i socialt arbete. I sin text lyfter Ranta-Tyrrkö hur de nordiska länderna varit en del av den europeiska kolonialismens expansionistiska ambitioner. Det tysta och uttalade stödet för och deltagande i produktionen av koloniala världsbilder, kunskap för legitimering av kolonial exploatering och ackumulering av kapital gör de nordiska länderna till en konkret och relevant del av det europeiska koloniala projektet och dess strukturer. I detta sammanhang, menar Ranta-Tyrrkö, är det viktigt att rannsaka och kontextualisera hur det sociala arbetets fält påverkats av sådana kunskaper, strukturer och relationer. 
I texten har vi börjat där vi står och jobbat med att lägga lager till lager i ett kritiskt och reflexivt samtal mellan oss, ett antal teoretiska begrepp och det sociala arbetet så som vi förstår dem. Textens inledning är gemensam, medan resterande delar skrivits fram i dialogform. Vi har olika erfarenhet från socialt arbete och aktivism. När vi skriver, gör vi det utifrån dessa erfarenheter och utifrån våra positioner och erfarenheter som lärare, forskare, doktorander och före detta studenter. Våra reflektioner i texten är både anspråkslösa, anspråksfulla och ansvarsutkrävande. Efter en stundtals både stökig, lustfylld och frustrerande process kom vi att utgå från tre centrala begrepp: kolonialitet, locus of enunciation och epistemicide. Texten är strukturerad i enlighet med tre övergripande teman: locus of enunciation - att positionera kunskapande, en vidareutveckling av för oss centrala begrepp, samt kolonialitet och socialt arbete. Vi inleder nedan med korta orienterande definitioner av de tre centrala begreppen, vilka sedan fördjupas vidare i texten.

Begreppet locus of enunciation har vi hämtat från Walter Mignolo (1999). Det innebär för oss de platser och erfarenheter där skapande av vår förståelse av världen och oss själva blir till och uttrycks. Med det tar vi fasta på att visa att vi tänker och skriver från tids- och rumsmässigt specifika sammanhang och geopolitiska platser, med specifika erfarenheter inhysta i olika kroppar och språk. Kontexten är en kolonialt designad global kapitalism. Att begreppsliggöra sådana utgångspunkter blir ett sätt att synliggöra dominerande kunskapsparadigm: visa på förkroppsligad kunskap snarare än att tala genom (den enda) rösten från ingenstans.

Begreppet kolonialitet refererar till hur dominans etableras genom makt sprungen ur europeisk kolonialism (Quijano 2000b). Makten utövas genom social klassificering i form av raskategorier där kolonialiserade människor och territorier underordnas. Detta koloniala mönster uppbär också organisering av arbete och kapital lokalt och globalt. Kolonialismens exploaterings- och avhumaniseringsprocesser ses utifrån detta som en kontinuitet snarare än som avslutade. Koloniala band, strukturer och processer ses alltså som aktuella och som en realitet trots att många historiskt formella koloniala band har upplösts (vissa så sent som på 1980-talet). Ett begrepp som är nära sammankopplat med kolonialitet och locus of enunciation är epistemicide, alltså kunskapsmord (Mignolo 2013; de Sousa Santos 2016). Det syftar till hur kunskapsgörande till både form och innehåll är centralt för koloniala dominansprocesser. Det här sättet att se och göra kunskap har medfört (medför) att en diversitet av kunskapsformer och förståelser sprungna ur de kolonialiserade delarna av världen aktivt suddas bort. Därmed trängs mångfalden av former för vetande och vetandets grunder undan. Förtryckta och marginaliserade gruppers kamp, världsuppfattningar och överlevnad undergrävs, ifrågasätts och ses som illegitima eller omoderna i den västerniserade blicken. Begreppen vidareutvecklas i dialogen nedan som inleds med att vi skisserar våra respektive utgångspunkter. 


\section{Locus of enunciation: positionering av kunskapande}

\section{Hur och när kom vi till en förståelse av kolonialitet och socialt arbete?}

Lena Sawyer: Mina första möten med socialt arbete handlar om hur jag hörde mina grannar och släktingar prata om matkuponger och att få sin månatliga utbetalning från sociala myndigheter. Diskussionerna rörde vad som kunde och inte kunde köpas med dessa, väntan på att de skulle komma, hur de var tvungna att spara, glädjen när de kom och inte minst skammen och strategierna för att dölja att vara en mottagare av ekonomiskt stöd. Men jag lärde mig också om socialt (förändrings)arbete genom att delta inom olika sociala rörelser, idéburna organisationer, statliga verksamheter och genom social mobilisering. Begreppsmässigt kom min förståelse av kolonialitet att få en annan innebörd genom studier i ämnet kulturantropologi i USA och sedan som undervisande lärare i socialt arbete i Sverige de senaste 20 åren. Inom akademin mötte jag begrepp och tolkningsramar som både bekräftade och utvidgade den kunskap jag redan hade med mig, men jag mötte också begrepp och tolkningsmodeller som hotade att förvränga den, och som jag upplevde som våldsamt. Med det menar jag att jag känner igen mig i Saidiya Hartmans (2018 s. 220) beskrivning av svarta amerikanska kvinnors möte med offentliga historiska arkiv inom socialt arbete som ett möte med "the sociological imagination that could only ever recognize her as a problem".

Hanna Wikström: Jag är uppväxt i norra Sverige och bär med mig en rik flora av erfarenheter av rasism mot bland annat Tornedalingar, samer, romer, finska och turkiska arbetskraftsinvandrare, men tillhör inte själv någon av dessa grupper. Jag bär också med mig erfarenheten av norra Sverige som periferi (där solen alltid verkade lysa bara i Stockholm). När jag började forskarutbildningen i socialt arbete var det därför med den redan bestämda uppfattningen att sparka uppåt.

Men, jag är inte säker på att jag riktigt begripit vad socialt arbete är. Anledningar är ämnets tvärvetenskaplighet och bredd, liksom spänningen mellan det som kallas "fältet" och akademin - men även de många olika sätten att arbeta inom och betrakta socialt arbete. Enligt internationella definitioner ses fältet socialt arbete som en praktikbaserad profession och akademisk disciplin som bland annat ska verka för social förändring, mänskliga rättigheter och social rättvisa (IASSW, IFSW). Det finns en uppmaning om commitment to action och att inkludera historiska processer för att förstå hur sociala, politiska och ekonomiska ojämlikheter skapats och skapas. Jag ser koloniala processer som centralt för att förstå dessa sociala skeenden. Därför väcker definitionerna samtidigt frågor om hur imperativen om social förändring bärs upp, på vems villkor, på bekostnad av vad och vilka historiska och andra implikationer av makt som ligger i begreppen själva? I 
hur stor utsträckning gömmer sådana begrepp och ansatser lika mycket som de manar till handling genom att till exempel anta att "mänskliga rättigheter" kan och bör uttolkas av dem som inte själva far(it) illa i de processer man försöker åtgärda? Under mina år i socialt arbete, under forskarutbildningen och efteråt har jag kommit att förstå socialt arbete som ett motståndets praktik med beredskap att spåra och agera på ojämlikhet, förtryck och epistemiskt våld.

Adrián Groglopo: Det dekoloniala tänkandet och praxis är i grunden de kolonialiserades historiska bidrag sedan 1492 till att skapa en förståelse om kolonialismens centrala ontologiska och epistemologiska projekt av den moderna kapitalismen. Min egen ingång till detta tänkande går tillbaka till mitt avhandlingsprojekt. Även om jag tidigare hade varit i kontakt med bland annat Mignolos och Enrique Dussels arbeten, var min ingång till frågor om ras, rasism och kolonialism mer av den postkoloniala skolan och av den anglosaxiska teoribildningen critical race theory. Under en period av intensiv inläsning av latinamerikansk marxism - från José Carlos Mariateguis texter (1920-talet) till Latinamerikas beroendeskolan (mellan 1950- och 1970talen) - kom jag i kontakt med Quijanos texter. Där öppnades vägen till den dekoloniala skolan som i Latinamerika startades under 1990-talet och som i Sverige och resten av Europa inte hade särskilt stort gehör. Min avhandling behandlade frågan om kapitalinvesteringar från det globala nord till det globala syd (exemplifierat av Latinamerika), det vill säga global kapitalism reglerad av koloniala mönster. För att förstå vad som försiggick i Latinamerikas historia och nuvarande nykoloniala processer iscensatt genom transnationella företags appropriering av naturresurser, behövde jag ett annat sätt att förstå och teoretisera kapitalismen och kolonialismen än det postkoloniala och kritiska rasstudier kunde erbjuda. För min del var den västerländska marxismens betoning på ekonomistisk tolkning och renodlad teori om kapitalism inte tillräcklig för att förstå kolonialismens påverkan på dagens politiska och ekonomiska ojämlikheter i världen.

Maimuna Abdullahi: Diskussionen som uppstod vid examination av min C-uppsats vid socionomprogrammet 2012 var startskottet för min orientering $\mathrm{i}$ dekoloniala perspektiv då jag lämnades med frågan: Kan rasismen och spåren av kolonialismen vara så här tydligt ringande? Det verkade nämligen som att min studiekamrats finska och min somaliska bakgrund på något vis befläckade vår möjlighet att analysera hur rasstereotyper reproduceras i de dokument vi studerat. Kunde vi möjligtvis ha tolkat in för mycket i det som kunde utläsas? Möjligheten finns alltid. Men hur kommer det sig att bristande referensramar eller bristande erfarenheter av kolonialismens spår inte betraktas som ett tillkortakommande, väcker "misstankar" - eller åtminstone ses som en begränsning - för dessa kroppars 
kunskapsanspråk? Det var då som termer som locus of enunication och kolonialitet aktualiserades för mig. Det var inte förrän 2016 som jag fick en större förståelse för betydelsen av kolonialitet. Jag deltog i sommarskolan Critical Muslim Studies: Decolonial Struggles and Liberation Theologies i Granada. Utgångspunkten för sommarskolan var att synliggöra hur historiska parallellprocesser som kolonialiseringen av Granada (Al-Andalus) och kolonialiseringen av Las Americas lade grunden för en ny världsordning, och vars spår vi kan se i hur våra samhällen organiseras i dag. Även om jag fortsatte mina studier efter socionomexamen, så var det inte i akademin jag utforskade de frågorna. Det var genom mitt arbete med social mobilisering i det civila samhället som frågorna var högaktuella: växande "förortsrörelser" som diskuterade vad det innebär att vara jordens fördömda, arvet av kolonialismen i Sverige och globalt och vilka visioner om social, politisk och ekonomisk jämlikhet som är möjliga i ett land där rasism, men sällan några rasister, finns. Diskussionerna fördes inte bara inom civilsamhället, utan även med forskare. Det kan ha varit det som gav mig hoppet om att ändå inte helt ge upp hoppet om akademin och slutligen - även om ambivalent - söka mig till forskarutbildningen.

\section{Maktens kolonialitet, lines of flight och epistemicide}

\section{Hur påverkar våra olika ingångar och utgångspunkter våra förståelser av begreppen?}

Adrián Groglopo: Den dekoloniala skolan har sin grund i karibisk och latinamerikansk teoribildning. Den kommer från intellektuella i Karibien och Latinamerika som tänkt kapitalism, imperialism, kolonialism och modernitet från a locus of enunciation (den geopolitiska och kroppspolitiska kunskapsposition från vilken människor talar) i den geopolitiska position dessa regioner befunnit sig i sedan de kolonialiserades av Europa. Quijanos (2000a) begrepp maktens kolonialitet förklarar kolonialismens arv i samtiden och kom att bli utgångspunkten för det som benämns Modernitets/kolonialitetsgruppen. Maktens kolonialitet innebär för Quijano (ibid. s. 1) ett sätt att belysa "den sociala och universella klassificeringen av världens befolkning genom idén om ras" från den koloniala eran till modern tid. Den möjliggör maktens strukturer, kontroll och hegemoni som uppstod vid erövringen av Amerika och upprätthållits till modern tid. Maktens kolonialitet konfigurerar, enligt Quijano, alla områden av social existens, som arbete, produktion, reproduktion, kön och genus, subjektivitet och ledarskap. Kolonialitet och modernitet är, på så sätt, två sidor av samma mynt. 
Lena Sawyer: Ett annat centralt begrepp för förståelse av kolonialitet och socialt arbete är epistemicide (de Sousa Santos 2016). Begreppet lyfter fram hur utbildningsinstitutioners kunskapande har varit centralt för kolonialitet, där vissa begrepp, världsuppfattningar och förståelser premieras som kunskap samtidigt som andra kunskapsformer görs illegitima och aktivt suddas bort. Begrepp som epistemicide skänker ett erkännande av erfarenhet som studenter och lärare som tillhör marginaliserade grupper upplever i möte med utbildningsinstitutioner. Begrepp som epistemicide kan erbjuda en linje av flykt från ett eurocentriskt kunskapssystem och ge bekräftelse åt de erfarenheter och kunskapsformer vi bär med oss in i dessa utbildningsinstitutioner. Med det menar jag en förståelse för hur vissa modeller, begrepp och framskrivningar som används inom socialt arbete, om oss och våra familjer, är skapade ur koloniala förståelser. Det bidrar till förtryck, marginalisering och stigmatisering.

Maimuna Abdullahi: Jag ser begreppet epistemicide som en uppmaning att leta $\mathrm{i}$ kolonialismens spår. En öppning att se tillbaka på de historiska processer som möjliggör existensen av överlägsna och underlägsna epistemologier. Förutom att det handlar om uppvärderande av vissa vägar till kunskap medan andra nedvärderas, handlar det också om en aktiv inkluderings- och exkluderingsprocess av vilka som kan ingå i en kanon av tänkande (Grosfoguel 2013). Denna inkluderings- och exkluderingsprocess är ett resultat av den europeiska upplysningsfilosofins ställning i det Ramon Grosfoguel (2013 s. 75) betecknar som "the Westernized universities". Grosfoguel skriver om hur upplysningsfilosofins framväxt föregås av 150 år av en enorm mängd våld mot de kolonialiserade. Det är enligt Grosfoguel detta våldskapital som la grunden för den västerländska och "moderna" filosofin förknippad med den franska filosofen Rene Descartes och frasen: "Jag tänker, alltså finns jag", vilket skapade en radikalt ny grund för kunskap. Det utmanade kristendomens särställning som kunskapskälla sedan Romarriket och betraktade inte längre den kristna guden som kunskapskälla. Denna särställning var nu reserverad för detta nya "jag". Grosfoguel menar att detta uppdiktade "objektiva jag" bör förstås som den andra kolonialismen. Kolonisatören och den europeiska mannen steg upp, antog plattformen utifrån vilken världen kan betraktas på detta till synes genomskinliga sätt. Detta "jag" förmodas kunna producera sann kunskap bortom tid och rum och blir universellt i meningen kroppslöst, könlöst, färglöst och platslöst (Morsi 2017 s. 18).

Hanna Wikström: Att leta i kolonialismens spår, som Maimuna Abdullahi skriver ovan, innebär att också ogöra koloniala kunskapsformer. Inte bara dess innehåll. Frantz Fanon (1971/1995) menar att det inte går att riva herrens hus genom att använda herrens verktyg. För att skriva sig ur relationen mellan förtryckt och för- 
tryckande, måste ett språk och verktyg sökas bortom dessa inskrivningar och genom strategier som inte upprepar samma logik. Att inte endast vända upp och ner på herre-slav-relationen och göra slaven till herre och herren till slav och därigenom använda samma förtryckande verktyg - utan genom att rasera denna tudelade struktur. Strategier att montera ner makten över kunskapspositioner kan vara kollektivt skrivande eller arbete över gränser, att bredda kanon av röster med definitionsrätt, söka utgångspunkter i förtryckta perspektiv med syfte att skapa nya multipla formationer. Inom poststrukturalistisk feministisk teoribildning har figuren lines of flight använts med liknande intentioner. Den innebär att ta fasta på "frön", eller aspekter i undertryckta perspektiv, som skapar "flyktvägar" ur dominerande budskap och förhållningssätt. Genom att följa dessa lines of flight kan andra paradigm spåras, pekas ut och utvecklas.

Adrián Groglopo: Det är viktigt att påpeka de grundläggande aspekter som skiljer den dekoloniala och postkoloniala skolan åt. De uppstår i olika kontexter och utgår från skilda historiska moment. Den postkoloniala skolan etablerades av bland andra Edward Said, Gayatri Spivak och Homi Bhabha och utgår från den koloniala historien av brittisk och fransk imperialism och kolonial expansion som skedde runt 1700- och 1800-talen. Den dekoloniala skolan har i stället sin grund i Karibien och Latinamerika, med ett teoretiserande om kolonialismens arv som konstitutiv till det globala kapitalistiska systemet; som ett globalt mönster av kapitalismens expansion sedan 1492 då Columbus anlände till Abya Yala (Las Americas). Det handlar om en skillnad av trehundra år av kolonialstyre i Amerikas och Afrika, som med slavhandel och plundring av naturresurser förvandlade Europas medeltid till upplysningstid. Under 1500-talet i Europa började filosofiska, ekonomiska och politiska kunskaper produceras och etableras som universella. I samband med det konstruerades Europa utifrån tre centrala processer: a) konstruerandet av den kolonialiserade i Americas och Afrika som lägre och utan tillräcklig mänsklighet, b) konstruerandet av den Andra i Asien som exotisk och inte tillräckligt civiliserad och c) konstruerandet av Europas interna Andra som tillhörande medeltiden (Romero-Losacco 2017 s. 188). Det var i grunden ett kolonialt ontologiskt ramverk, som likställer den moderna europeiska människan - symboliserad i vit hud - som historiens centrala utgångspunkt för vad vetande, kunskap och människa innebar. Den kolonialiserade Andra blev konstruerad i den europeiska filosofin och politiska diskurser som lägre, exotisk och bakåtsträvande, som antingen djur eller submänniska, som kanske kan uppnå den moderna europeiska människans civilisation om den underordnar sig den vita människans rationalitet. Den epistemologiska utgångspunkten i den dekoloniala skolan utgår från de kolonialiserades kunskaper och kollektiva erfarenheter om de maktsystem som de underordnats i. Det är ett perspektiv som delvis kan förstås 
utifrån tredje världens antikoloniala marxistiska fält och delvis utifrån ursprungsbefolkningens kunskaper om antikolonialt motstånd. I det dekoloniala tänkandet är kolonialismen inte en "post", utan det är ett levande materialistiskt system konstitutiv av den globala kapitalismen och som har faktiska konsekvenser för jordens fördömda.

Hanna Wikström: Jag har huvudsakligen närmat mig socialt arbete genom postkolonial teoribildning. Begreppet dekolonial är relativt nytt för mig, däremot inte de tankeformationer det refererar till. Det är tydligt att de två ganska spretiga fälten epistemologiskt delar världsbild och de teoretiska figurationerna och epistemen genom vilka de närmar sig historien och världen i allt väsentligt är desamma. Det som skiljer företrädare inom de båda fälten åt är i vilken utsträckning materiella förhållanden respektive föreställningar (diskurser) om verkligheten accentueras. Sådana ontologiska antaganden ger bland annat olika synsätt på strategier för förändring. Båda fälten förlitar sig dock på både diskursiva och materiella ansatser i olika grad. En lång rad författare spänner över, används och går att använda på en mängd olika sätt eftersom deras texter utgör konglomerat med lån från både diskursiva och materialistiska ansatser. Fälten förenas genom sitt fokus på att förändring uppnås, och strukturer vittrar genom betoning på både nya former för att nå kunskap, nytt kunskapsinnehåll och reell omstrukturering. Att visa hur bortsuddanden går till, blir lika viktigt som att visa att och vad som suddas bort. Att de- eller avkolonialisera är ett verb och en aktivitet där det blir lika viktigt att dekolonialisera det egna tänkandet som yttre strukturer.

\section{Kolonialitet och socialt arbete}

\section{Hur kan vi tänka kring fältet socialt arbete utifrån en förståelse av kolonialismens betydelse?}

Hanna Wikström: Både teoribildningen vi berör och socialt arbete är konglomerat. Olika vägval, positioner och strategier är möjliga att göra och inta. Vad vill jag att studenter, presumptiva läsare och socialarbetare ska ha med sig? Som lärare och forskare har jag ett otvetydigt formuleringsprivilegium. Men det är ett kringgärdat privilegium. Av både sociala och andra maktstrukturer (kursplaner, riktlinjer, konkurrensen om forskningsmedel), men inte minst, av själva det vetenskapliga och epistemiskt upprättade system jag är tränad i och befinner mig inom. Jag är tränad i precis de principer de dekoloniala ansatserna avser att angripa. Därför blir mina strategier för att förskjuta, störa och leta andra möjligheter en balansgång i gränslandet mellan 
positioneringen inom, och något som kan bli till på gränsen och bortom detta inom. I utrymmet jag har och skapar är appellen till känslor lika viktig som logiken för att skapa förståelse, för att nå fram och visa epistemicides. Att peka på allas vår sårbarhet, sorg, styrkor, frustration, förmåga till vrede och lust blir en sorts lines of flight, frön som kan fås att gro.

Adrián Groglopo: I frågan om vad socialt arbete är, kan vi se hur den svenska staten historiskt varit central för välfärdsinsatser. Välfärdsstaten har varit viktig för att "täcka upp och underlätta" livet under de skräckkabinett som skapas i kapitalismens kölvatten i form av fattigdom, arbetslöshet, klasskillnader samt social och politisk ojämlikhet. Samtidigt har den svenska välfärdsstaten visat sin koloniala sida under historien, till exempel i hanteringen av romer, samer och funktionshindrade samt även i dag migranter och flyktingar. Så jag frågar: Vilka verktyg har socialt arbete arbetat med? Som sociolog och antirasistisk aktivist uppskattar jag disciplinens vilja att sträva för social förändring vilket är något jag lyfter i olika undervisningsmoment. Det blir också viktigt att väcka frågor hos studenterna om vad social förändring är. Vilken sorts förändring eftersträvas? För vilka ska förändring ske? Kan det ske endast genom lagar och regler? Uppnås det bara genom statlig kontroll? Och vilka andra möjliga strategier finns för en samhällsförändring? Det är en uppsjö av frågor som jag fortfarande försöker reda ut och förstå och som är viktiga att diskutera med studenter och praktiker i fältet.

Lena Sawyer: Jag tänker att närma sig socialt arbete genom begreppet epistemicide är ett sätt att leta (i) kolonialismens spår. Att ifrågasätta vad som presenteras, hur det presenteras och vilka epistemologiska och ontologiska grunder dessa kunskapsformer vilar på. Det innebär att försöka synliggöra var vi själva kunskapar ifrån. I vår (Fahlgren \& Sawyer 2011) analys av den populära Socialt arbete. En grundbok (Meeuwisse, Sunesson \& Swärd 2006) argumenterade vi att författarna genomgående i texterna positionerade sig och talade till läsaren i form av "vi" "vår" och "oss". Vi kände ibland inte igen oss i antagandet att "vi" hade gemensamma referenser, utgångspunkter och erfarenheter. Som läsare ställde vi oss frågan: Vem är den tilltänkta läsaren och vilka erfarenheter tänktes vi och blivande socionomer dela?

Dessa frågor blev ingången till vår studie där analysen visade att användningen av ordet "vi" bland annat implicerade manliga, vita och sekulära läsare och framför allt en blivande socialarbetare från medelklassen. De tänkta läsarna presenterades som utan erfarenheter av att själva ha varit föremål eller mottagare av välfärdsstatliga insatser inom socialt arbete. Det vill säga människor utan erfarenhet av klientskap, fattigdom och utsatthet. Begreppet epistemicide i relation till studiens resultat 
kan ses som en uppmaning för lärare att sträva efter att reflektera och synliggöra sin locus of enunciation när vi undervisar och forskar, att skriva fram vad det innebär att ta för givet vissa erfarenheter och positioner som vi oftast oreflekterat utgår ifrån. Och genom att göra så visar vi upp det partiella i alla former av kunskapande och att även våra privilegierade positioner innebär osynliggörande.

Adrián Groglopo: Jag tänker att denna typ av distans och tänkta objektivitet varit mottot för vetenskapliga principer i den långa historien av kolonial och imperialistisk vit dominans och överlägsenhet. En huvudprincip i detta koloniala episteme har varit att skapa en ontologisk skiljelinje mellan vilka kategorier som förstås/behandlas som människor och vilka som förstås/behandlas som submänniskor eller ickemänniskor. Politiska redskap för att upprätthålla en sådan ontologisk skiljelinje har varit och är segregation, apartheid, rashierarkier och den globala rasarbetsdelningen. I objektivitetens namn har de kolonialiserade omvandlats till objekt för studier, experiment, observationer och politiska handlingsplaner som historiskt har sträckt sig från policyer om inkludering till policyer om förintelse. Västvärlden är ett bra historiskt exempel.

Hanna Wikström: Jag ser våldet, utsuddandet, särskiljandet, avskiljandet uttryckt i undervisningens seminarierum så gott som dagligen. Jag blir rörd, känner skam och vördnad när studenter med erfarenheter av insatser i socialt arbete kommer ut som objekt för det sociala arbetets insatser och använder dessa erfarenheter för att teoretisera och tänka i och om det sociala arbetet. Skam därför att det inte ses som en självklar och viktig erfarenhet att använda sig av inom socialt arbete. Stolthet för att de ändå lyckas komma ut och ogöra bortsuddandet av denna typ av positioner. Jag känner ofta att jag inte nog tydligt lyckas förmedla att det är så otroligt viktigt att ha tillgång till de här, allas våra olikartade positioner av sårbarhet och maktlöshet, att låta marginaliserade positioner bli en självklar del i det sociala arbetets gemensamma erfarenhetsbas och kunskapsbyggande. Mina egna känslor av sårbarhet, maktlöshet, sorg, skam och vrede är några av mina viktigaste arbetsverktyg i socialt arbete.

Lena Sawyer: En av mina strategier som lärare har varit att söka kunskapande former som förhoppningsvis berör och är vackra och på det sättet öppna upp för det sårbara (Nash 2019). Det kan handla om skrivandet, exemplifieringar, att försöka väcka en känsla, att försöka erkänna en erfarenhet i akademiska rum, att avslöja akademins begripliggörande som förankrad i tid och rum. En förståelse av maktens kolonialitet erbjuder också möjligheten att utmana metodologier; till exempel positivismens observation och kategorisering som vägen till vetande och därmed öppna upp för andra tillvägagångssätt och sinnen som att lyssna och känna (Campt 2017; Sawyer \& 
Osei-Kofi 2020). Det innebär att även formen för kunskapande utmanas, eller som Mignolo (2013) uppmanar, att vara epistemiskt olydig. Det kan betyda att formen för kunskapande som strävar efter att avvika från den moderna idén om framsteg och förnuft kanske inte bara kan, utan också bör följa en annan linje (Tsing 2015). En sådan linje erbjuder en linje av flykt från socialt arbetes starka positivistiska rötter och som kan visas genom den återkommande frågan "Får jag använda jag när jag skriver?" från studenter. Mitt självklara "ja!" handlar om att något inte blir mer objektivt för att det saknar avsändare eller för att avsändaren framstår som distanserad från sin utsaga. "Jaget" påminner i stället om att vi alla skriver från en specifik plats. Att försöka reflektera utifrån just din plats för talande och kunskapande, din erfarenhet och positionering i samhället och världen är en viktig början.

Hanna Wikström: Jag tror att de mest värdefulla kunskapsresorna och kunskapandet börjar i de egna erfarenheterna och inte långt bort från dem. De kan tas till vara och ges plats i undervisningen på olika sätt beroende på tema. Att skicka ut studenter på en spårvagnsresa tvärs över Göteborg för att uppmärksamma den segregerade staden och relatera detta till egna erfarenheter och den egna positionen är ett sätt att tvingas ta plats mitt ibland det som iakttas. Att fundera över hinder och privilegier i det egna livet i relation till de sociala strukturer vi pratar om $i$ undervisningen är ett annat. Att lyssna på radioinslag och se på film är ytterligare försök att bryta upp och ner de teoretiska texterna till något som studenter kan omvandla baserat på känslor, erfarenheter i sina egna liv och teori och handling. Jag vill också förmedla, såväl i forskning som i undervisning, att allt går, så länge man vet vad man frångår och förhandlar och förhåller sig till när man gör det.

Maimuna Abdullahi: En dekolonial ingång till att forska i socialt arbete öppnar upp för att bryta den här typen av inbyggd lojalitet med den cartesianska filosofin. Men jag ställer mig undrande till om denna lojalitet inte redan bryts också genom andra existerande kritiska perspektiv och ansatser i socialt arbete. Jag tänker exempelvis på ansatser som utmanar det positivistiska forskningsparadigmet genom att marginaliserade grupper situeras som forskningssubjekt snarare än forskningsobjekt. Jag ställer mig själv frågan: Vad erbjuder en dekolonial ansats i ett ämne som socialt arbete som är spretigt både som ett forskningsämne och som praktik? Jag tänker att i en forskarutbildning i socialt arbete betyder en dekolonial ansats ambitionen att avslöja den hegemoni som är ett resultat av kolonialitet och som kan göra sig påmind i det egna forskningsprojektet. Den centrala betydelsen av en dekolonial ansats i socialt arbete är alltså behovet av avlänkning på epistemisk nivå, på nivån för produktion av kunskap (Mignolo 2013). 


\section{Avslutande reflektioner}

Genom vår dialog har vi försökt närma oss en förståelse för kolonialismens relation till socialt arbete som ämne genom att skriva fram, och ifrån, våra specifika locus of enunciations. I dialogen har plats, kontext, erfarenheter, språk, geografi, epistemologiska grunder och utbildningsämne framträtt som centrala. Därefter har vi fortsatt dialogen med att lyfta för oss viktiga begrepp och beskrivit hur vi förankrar olika epistemologiska och vetenskapsteoretiska traditioner i vår förståelse av kolonialitet. Vi har gett förslag på begrepp som vi finner fruktbara och relevanta i och för socialt arbete och reflekterat över hur vi kunnat använda och se deras relevans för socialt arbete. På det sättet har vi gett några exempel på öppningar mot både rent konkret arbete i klassrum och med studenter, men också mot visioner och tankar om andra vägar till kunskapande, varande och lärande. Det är vår förhoppning att essän genom både innehåll och form kan inspirera läsaren att (fortsätta) söka egna sätt att ta sig an liknande angreppssätt och dekoloniala praktiker. Ett förslag vi otvetydigt lämnar är att söka och göra marginaliserade positioner (känslor, erfarenheter, tillvägagångssätt) till utgångspunkt för nya vägar ut ur koloniala paradigm. 


\section{Referenser}

Campt, T. (2017) Listening to images. Durham, North Carolina: Duke University Press.

de Sousa Santos, B. (2016) Epistemologies of the South and the future. From the European South, (1): 17-29.

Fahlgren, S. \& Sawyer, L. (2011) The power of positioning: On the normalisation of gender, race/ ethnicity, nation and class positions in a Swedish social work textbook. Gender and Education. 23(5): 535-548.

Fanon, F. (1971/1995) Svarta hud, vita masker [ny utg.] Stockholm: Daidalos.

Grosfoguel, R. (2013) Epistemic racism/sexism, westernized universities and the four genocides/ epistemicides of the long 16th century. Human Architecture: Journal of the Sociology of SelfKnowledge, 11(1): 73-89.

Hartman, S. (2018) Wayward lives, beautiful experiments. Intimate histories of riotous black girls, troublesome women, and queer radicals. New York: W. W. Norton \& Company.

International Association of Schools of Social Work, International Federation of Social Work (IASSW \& IFSW) (2014) Global definition av socialt arbete. https://www.ifsw.org/wp-content/ uploads/ifsw-cdn/assets/ifsw_124418-5.pdf [Hämtat: 2020-08-17].

International Federation of Social Work; International Association of Schools of Social Work \& International Council on Social Welfare (IFSW, IASSW \& ICSW) (2012) The global agenda. For social work and social development commitment to action. http://cdn.ifsw.org/assets/ ifsw_23031-6.pdf [Hämtat: 2020-08-17].

Meeuwisse, A., Sunesson, S. \& Swärd, H. (2006) Socialt arbete. En grundbok. Stockholm: Natur \& Kultur Akademisk.

Mignolo, W. (1999) I am where I think. Epistemology and the colonial difference. Journal of Latin American Cultural Studies, 8(2): 235-45.

Mignolo, W. (2013) Geopolitics of sensing and knowing. On (de)coloniality, border thinking, and epistemic disobedience. Confero, 1(1): 129-150.

Morsi, Y. (2017) Radical skin, moderate masks. De-radicalising the muslim and racism in post-racial societies. London: Rowman \& Littlefield International.

Nash, J.C. (2019) Writing black beauty. Signs: Journal of Women in Culture and Society, 45(1): $101-122$.

Quijano, A. (2000a) Colonialidad del poder, globalización y democracia. Revista Umbral. Diciembre del 2000. http://umbral.uprrp.edu/wp-content/uploads/2018/10/colonialidad20del20poder20globalizacic3b3n20y20democracia.pdf [Hämtat: 20/8/20]

Quijano, A. (2000b) Coloniality of power, eurocentrism and Latin America. Nepantla: Views from the South, 1(3): 533-580.

Ranta-Tyrkkö, S. (2011) High time for postcolonial analysis in social work. Nordic Social Work Research, 1(1):25-41.

Romero-Lossaco, J. (2017) "El fetichismo del Capital-Estado-Nación: de la transcrítica a la transmodernidad", Transmodernity, Spring, 187-210.

Sawyer, L. \& Osei-Kofi, N. (2020) "Listening" with Gothenburg's iron well. Engaging the imperial archive through black feminist methodologies and arts-based research. Feminist Review, 125(1): $54-61$.

Tsing, A. (2015) The mushroom at the end of the world. On the possibility of life in capitalist ruins. Princeton: Princeton Press. 